\title{
Coexistence of rheumatoid arthritis and ankylosing spondylitis
}

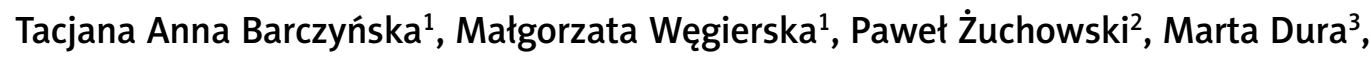 \\ Joanna Zalewska ${ }^{1}$, Marzena Waszczak ${ }^{4}$, Sławomir Jeka ${ }^{1}$
}

${ }^{1}$ Clinic of Rheumatology and Systemic Connective Tissue Disorders, J. Biziel University Hospital No. 2, Bydgoszcz, Ludwik Rydygier Collegium Medicum in Bydgoszcz, UMK in Torun, Poland

${ }^{2}$ Independent Section of Scientific Research Coordination, J. Biziel University Hospital No. 2, Bydgoszcz, Poland

${ }^{3}$ Department of Radiology, J. Biziel University Hospital No. 2, Bydgoszcz, Poland

${ }^{4}$ Centre for Clinical Trials, Warsaw, Poland

\begin{abstract}
Rheumatoid arthritis (RA) and ankylosing spondylitis (AS) are chronic progressive inflammatory diseases, leading to joint damage and reducing the physical fitness of patients. They are among the most common rheumatic diseases. However, their etiology and symptomatology are different. Formerly, AS was often wrongly diagnosed as RA. Today there are no major diagnostic difficulties in differentiation between these diseases, thanks to modern laboratory tests and imaging. However, a problem may arise when the patient has symptoms typical for both diseases simultaneously. Cases of coexistence of RA with AS - according to our best knowledge - are rare. This study aims to compare our experience in diagnosis and treatment of concomitant RA and AS with the experience of other researchers. Implementation of the proper diagnostic algorithm, allowing for correct diagnosis of both diseases in one patient, may be useful for differential diagnosis of similar cases in the future.
\end{abstract}

Key words: rheumatoid arthritis, ankylosing spondylitis, sacroiliitis.

\section{Introduction}

Rheumatoid arthritis (RA) and ankylosing spondylitis (AS) are among the most common rheumatic diseases. Chronic inflammation leads to progressive joint destruction and ultimately to the development of disability. Etiopathogenesis of both diseases has not been fully established. It is known that genetic predispositions to these diseases are different. The presence of HLA-B27 predisposes to AS, whereas HLA-DR4 frequently occurs in patients with RA [1]. Immunological factors are also of high significance. The first known serological marker for differentiating these two diseases was the rheumatoid factor (RF). It has been used in the diagnosis of RA since the 1950s [2]. Nowadays, it is useful to determine the level of antibodies against cyclic citrullinated peptides (anti-CCP), the presence of which supports the diagnosis of RA [3]. Coexistence of RA and AS in one patient is rare.
The most numerous descriptions of such patients come from the 1970s and 80s [4].

New diagnostic methods allow for more precise differentiation, diagnosis and inclusion of appropriate treatment, based on the following criteria: modified New York criteria for diagnosis of AS from 1984 and RA classification criteria of the ACR/EULAR (American College of Rheumatology/European League Against Rheumatism) of 2010 [3].

Own experience in the diagnosis of concurrent RA and AS shall be presented based on the cases of three patients (Table I).

\section{Case 1}

In case 1 the patient, diagnosed with RA 20 years earlier, reported pain and swelling of symmetrical joints of the hands (metacarpophalangeal [MCP], proximal interphalangeal [PIP]) and feet, left wrist, left hip pain, 
Table I. Characteristics of patients

\begin{tabular}{|c|c|c|c|}
\hline Patients & 1 & 2 & 3 \\
\hline Gender & female & male & male \\
\hline Age (years) & 55 & 56 & 65 \\
\hline $\begin{array}{l}\text { Antibodies } \\
\text { anty-CCP } \\
\text { (norm 0,0-5,0 U/ml) }\end{array}$ & $\begin{array}{l}->600.0 \mathrm{U} / \mathrm{ml} \\
-1056.0 \mathrm{U} / \mathrm{ml} \\
\text { positive results }\end{array}$ & $\begin{array}{c}0.90 \mathrm{U} / \mathrm{ml} \\
\text { negative result }\end{array}$ & $\begin{array}{c}3.6 \mathrm{U} / \mathrm{ml} \\
\text { negative result }\end{array}$ \\
\hline $\begin{array}{l}\text { RFlgM } \\
\text { (ELISA method; } \\
\text { negative < } 20 \mathrm{RU} / \mathrm{ml})\end{array}$ & $\begin{array}{l}>200.0 \mathrm{RU} / \mathrm{ml} \\
\text { positive result }\end{array}$ & $\begin{array}{l}>200.0 \mathrm{RU} / \mathrm{ml} \\
\text { positive result }\end{array}$ & $\begin{array}{c}73.6 \mathrm{RU} / \mathrm{ml} \\
\text { positive result }\end{array}$ \\
\hline $\begin{array}{l}\text { Antigen } \\
\text { HLA-B27 }\end{array}$ & positive & positive & positive \\
\hline X-rays of hands and feet & $\begin{array}{l}\text { changes typical for RA stage } \\
\text { III / IV by Steinbrocker }\end{array}$ & $\begin{array}{l}\text { changes typical for RA stage } \\
\text { III by Steinbrocker }\end{array}$ & $\begin{array}{c}\text { changes typical for RA stage II by } \\
\text { Steinbrocker }\end{array}$ \\
\hline X-ray of sacroiliac joints & $\begin{array}{c}\text { features of ankylosis at the } \\
\text { sacroiliac joints (sacroilitis } \\
\text { bilateralis IV/IV) }\end{array}$ & $\begin{array}{c}\text { features of ankylosis at the } \\
\text { sacroiliac joints (sacroilitis } \\
\text { bilateralis IV/IV) }\end{array}$ & sacroilitis bilateralis III/II \\
\hline X-ray of the spine & $\begin{array}{l}\text { cervical spinal fusions on the } \\
\text { level of vertebral pedicles }\end{array}$ & $\begin{array}{l}\text { squaring of vertebral bodies } \\
\text { and ossification of the ante- } \\
\text { rior longitudinal ligaments at } \\
\text { C3-C4-C5-C6-C7 levels. }\end{array}$ & $\begin{array}{l}\text { a bony bridge on the level of } \\
\text { Th10 and Th11 vertebral bodies; } \\
\text { a syndesmophyte on the lateral } \\
\text { edge of L3 vertebral body }\end{array}$ \\
\hline
\end{tabular}
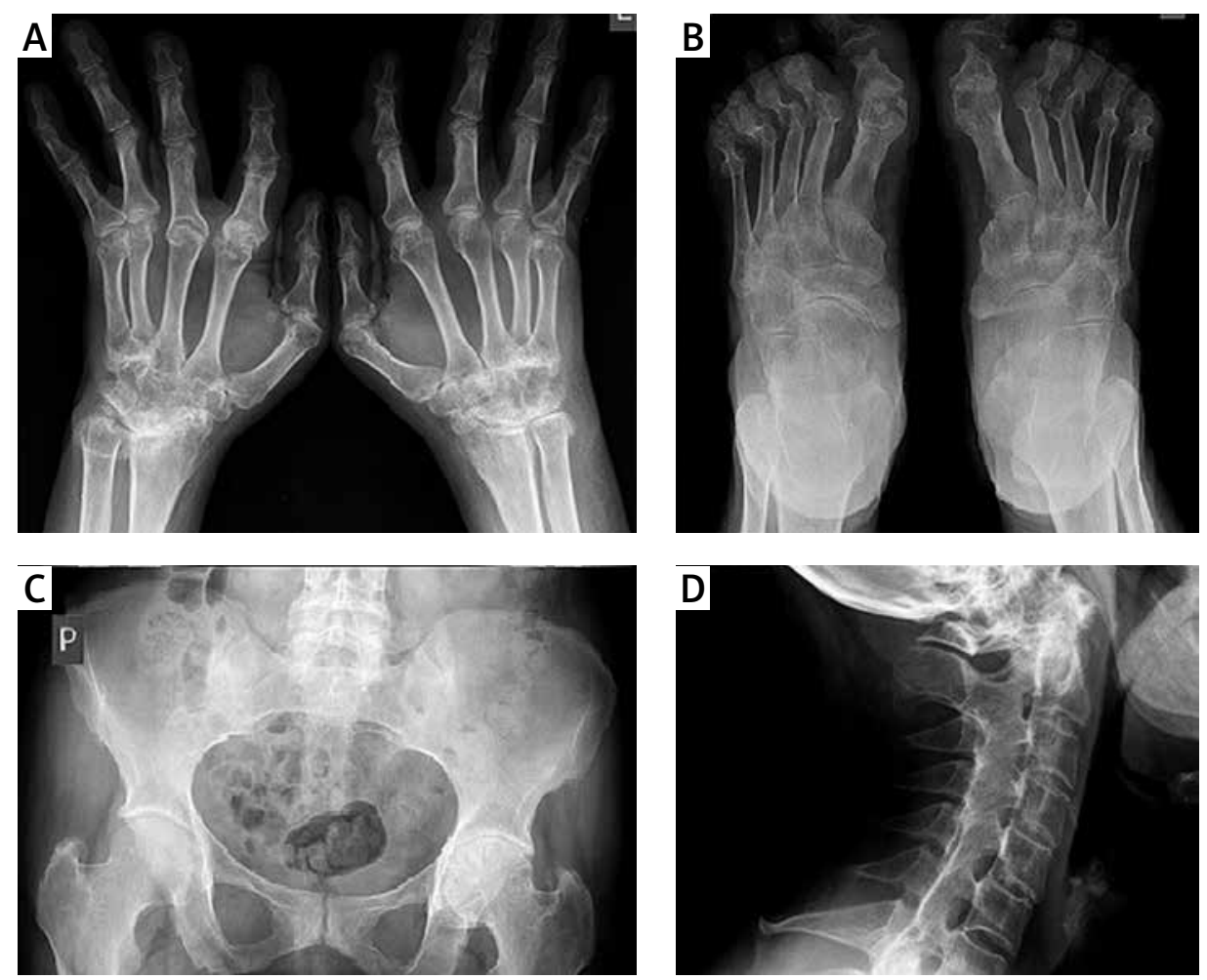

Fig. 1. X-rays - case 1. Advanced inflammatory and destructive changes indicative of ankylosis in both wrists. Subluxation and inflammatory changes with erosions in the MCP joints (A). Subluxation and inflammatory changes with erosions in the MTP joints (B). Ankylosis of the sacroiliac joints (C). Cervical spinal fusions on the level of vertebral pedicles (D). 
cervical and thoracic back pain in the lumbosacral area radiating to the groins and buttocks, during her hospitalization in 2013. Back and neck pain was of inflammatory nature, with significant exacerbation of symptoms for the last 18 months. Morning stiffness persisted for over 1 hour. The physical examination revealed signs of symmetrical arthritis, swelling, distortion and pain of wrist joints, MCP, PIP, ulnar deviation of the fingers, atrophy of the interosseous muscles of the hand, decreased mobility of wrist joints and hip joints (mainly the left one), subluxation, pain and swelling of the metatarsophalangeal joints (MTP) and rheumatoid nodule in the area of PIP joint II of the left hand. Furthermore, limited spinal mobility was observed, mainly in the cervical section (turn 10 degrees right, 10 degrees left) and chest, Ott's sign: $0 \mathrm{~cm}$, Schober's test: $3.5 \mathrm{~cm}$, chest respiratory expansion: $3.0 \mathrm{~cm}$, the occiput-to-wall distance: $0 \mathrm{~cm}$, fingertip-to-floor distance: $10 \mathrm{~cm}$, intermalleolar distance: $82 \mathrm{~cm}$, positive pain provocation tests: compres- sion, distraction, Gaenslen, Patrick and Mennell on the left. The immunological studies have shown high values of anti-CCP antibodies (> 600.0 U/ml and $1056.0 \mathrm{U} / \mathrm{ml}$ ), and RF-lgM (> $200 \mathrm{RU} / \mathrm{ml}$ ) twice. Genetic tests showed the presence of HLA-B27 and lack of HLACw6, which is typical for psoriasis (Fig. 1).

\section{Case 2}

The patient's first symptoms of AS occurred at the age of 34. It was a typical inflammatory back pain (IBP) and a feeling of morning stiffness lasting $>1$ hour. After about 14 years, the patient began to experience symptoms of symmetric inflammation of the peripheral joints, including small joints of the hands (MCP, PIP) and feet (MTP), wrists - mainly the left wrist and the right hip. The immunological test revealed high levels of RF IgM (> 200 $\mathrm{RU} / \mathrm{ml})$ and negative anti-CCP $(0.90 \mathrm{U} / \mathrm{ml})$. Presence of HLA-B27 was confirmed (Fig. 2).
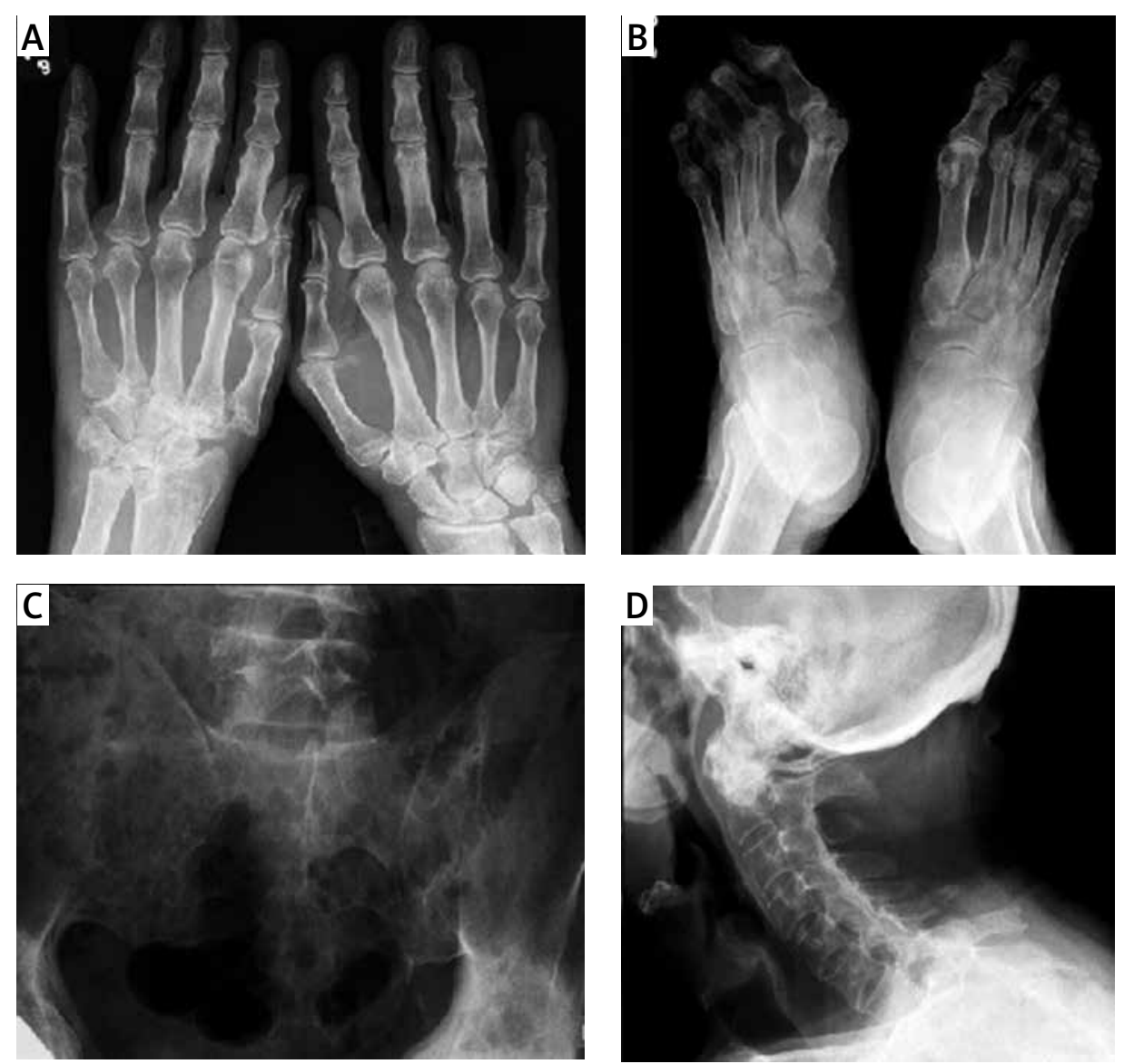

Fig. 2. X-rays - case 2. Advanced inflammatory and destructive changes with erosions in the right wrist (A). Subluxation, inflammatory and destructive changes with erosions in the MTP joints (B). Ankylosis of the sacroiliac joints (C). A tendency to squaring of the vertebral bodies, ossification of the anterior longitudinal ligaments at C3-C4 and C5-C6-C7 (D). 

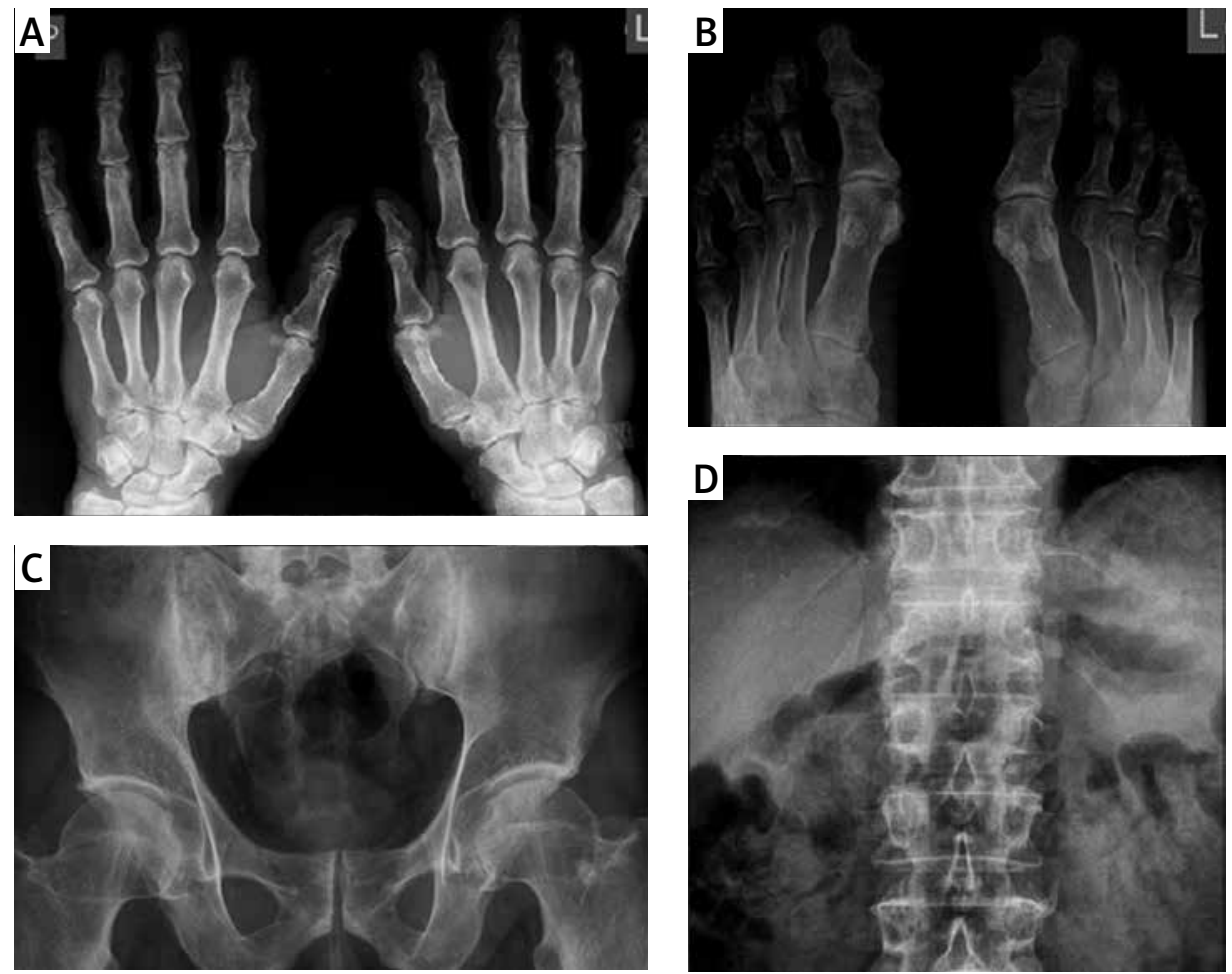

Fig. 3. X-rays - case 3. Degenerative lesions in the DIP joints (A). In the feet bones - osteoporosis and minor erosion at the base of the proximal phalanx of the finger and the left foot (B). Bilateral sacroiliitis grade III/II (C). A bony bridge on the right side edge of Th10 and Th11 vertebral bodies. A syndesmophyte on the left side edge of $L 3$ vertebral body (D).

\section{Case 3}

Case 3 - the patient had signs of inflammation of symmetric hand joints (MCP) and the MTP joints of the left foot, as well as a feeling of morning stiffness $>1$ hour. The patient reported IBP, and pain in the shoulders and hips for many years.

The immunological tests showed high levels of RFIgM (> 73.6 RU/ml), anti-CCP was negative $(3.6 \mathrm{U} / \mathrm{ml})$, and presence of HLA-B27 was confirmed (Fig. 3).

On the basis of the whole clinical image and the results of additional tests, all patients were diagnosed with coexisting RA and AS. Other types of spondyloarthropathy (SpA), including psoriatic arthritis, were excluded (Table II).

\section{Discussion}

In the general population, RA and AS occur with a comparable frequency from 0.3 to $1.5 \%$ [5]. Female sex is associated with a greater likelihood of developing RA, and male sex is associated with a greater likelihood of developing AS [5]. RA is usually diagnosed at the age of 40-50, whereas symptoms characteristic of AS start appearing before the age of $30[3,6]$. Pathogenesis of these diseases has not yet been fully clarified. Epidemiological data, as well as higher incidence of both RA and AS in certain families and identical twins, support the significance of genetic factors. In the case of RA, HLA-DR1 and HLA-DR4 are thought to be of fundamental importance [6]. This applies particularly to smokers with a positive anti-CCP. Approximately $60 \%$ of the risk of RA may be attributed to genetic factors. HLA-DRB1 is also frequently detected in AS [1]. However, the closest relationship was confirmed for AS and HLA-B27. The first such observations were reported in 1973 [7]. No relationship was revealed between HLA-B27 and RA. The research by Toussirot et al. [4] shows that $6.6 \%$ of patients with RA may have positive HLA-B27, which is comparable to the general population, wherein the expression of this antigen is $5-8 \%$. The presence of HLA-B27 in patients with RA does not increase the incidence of enthesitis or sacroiliac joint inflammation [4, 8, 9]. The percentage of people with positive HLA-B27 who can develop AS did not exceed $5 \%$, whereas this antigen is detected in up to 90-95\% of Caucasians suffering from AS [1]. This proves the significant impact of environmental and immunological factors on the occurrence of the disease in genetically predisposed individuals. Both in RA and AS, there 
Table II. Rheumatoid arthritis classification criteria according to ACR/EULAR 2010 and the modified New York criteria for diagnosis of AS of 1984 with respect to the patients described

\begin{tabular}{|c|c|c|c|}
\hline \multicolumn{4}{|c|}{ RA classification criteria according to ACR/EULAR 2010} \\
\hline Patients & 1 & 2 & 3 \\
\hline Joints involvement & 5 points & 5 points & 3 points \\
\hline Serology RF or anti-CCP & 3 points & 3 points & 3 points \\
\hline $\begin{array}{l}\text { Indicators acute phase: } \\
\text { CRP levels increased or accelerated ESR }\end{array}$ & 1 point & 1 point & 1 point \\
\hline The duration of symptoms $>6$ weeks & 1 point & 1 point & 1 point \\
\hline Certain diagnosis of $\mathrm{RA} \geq 6$ points & 10 points & 10 points & 8 points \\
\hline \multicolumn{4}{|c|}{ The modified New York criteria for diagnosis of AS of 1984} \\
\hline $\begin{array}{l}\text { Clinical criteria: } \\
\text { 1. Lumbosacral pain persisting for }>3 \text { months, which decreases after exercise, } \\
\text { and is not relieved at rest }\end{array}$ & + & + & + \\
\hline 2. Limited mobility of the lumbar spine at the sagittal and coronal plane & - & - & - \\
\hline 3. Limited mobility of the chest & + & + & + \\
\hline $\begin{array}{l}\text { Radiological criterion: } \\
\text { 1. Bilateral inflammatory changes in the sacroiliac joints at } 2^{\text {nd }}-4^{\text {th }} \text { degree or } \\
\text { 2. Unilateral at } 3^{\text {rd }}-4^{\text {th }} \text { degree }\end{array}$ & + & + & + \\
\hline $\begin{array}{l}\text { Certain diagnosis: } \\
\text { Radiological criterion and } \geq 1 \text { clinical criterion met }\end{array}$ & + & + & + \\
\hline
\end{tabular}

is increased production of pro-inflammatory cytokines such as tumor necrosis factor (TNF) [10]. The role of TNF in RA and AS was also confirmed by effective treatment with inhibitors of this cytokine.

In the clinical image of RA, the most characteristic symptom is symmetrical inflammation of numerous small joints of the hands and feet, most often the PIP and MCP joints, wrist joints and MTP joints. The feeling of morning stiffness usually lasts more than one hour. As the disease progresses, characteristic deformities of fingers and toes occur [6]. However, in patients with AS, peripheral arthritis is observed in about one third of cases. Changes are usually asymmetric and typically involve a single large joint, such as the shoulder joint, hip or knee joints. Erosions are rarely observed [6, 11]. AS is classified as axial spondyloarthropathy (aSpA), dominated by symptoms of bilateral arthritis of sacroiliac joints, as well as ligaments and all segments of the spine. A characteristic symptom is IBP accompanied by a feeling of stiffness in the morning. Following the ongoing disease process, eventually the cracks of sacroiliac joints become overgrown and spinal fusion occurs [6]. In RA, sacroiliac joint inflammation is rare, although according to some researchers, it may affect up to $20 \%$ of patients [12]. The differences in radiological image, however, are quite significant. In RA, ankylosis of sacroiliac joints is rarely observed, the changes are located in distal sections and the degree of damage is lower [4]. Inflammatory changes in the spine in patients with RA are most often observed in the upper cervical spine. They concern the atlanto-occipital joint and atlanto-axial joint, and they may lead to instability of these joints. There is a correlation between the amount of erosions in the joints of hands and inflammatory lesions at the atlanto-axial joint [13]. Presence of rheumatoid nodules is characteristic for RA, particularly in the sero-positive RA, whereas they are not observed in patients with AS [4]. The serological markers characteristic of RA include the RF and anti-CCP. Their presence is one of the criteria for the classification as RA. RF occurs in $70-85 \%$ of cases of RA [14]. However, it is characterized by low specificity. The frequency of the RF in the general population increases with age. It is detected in many other diseases [3]. In principle, it should not be present in seronegative SpA. It is rare, however, that RF is positive in patients with AS. It is then of low titer.

In studies by Tuossirot et al. [4], the RF was positive in $8.3 \%$ of patients with AS and in $9.8 \%$ of the control group - the difference was not statistically significant. A much more specific marker of RA is antibodies against citrullinated peptides, observed in $60-70 \%$ of patients with RA [3]. In the presented patients, the presence of RF at high titer was confirmed using enzyme immunoassays. In contrast, anti-CCP antibodies were present only in the case of the first patient, which was confirmed by two independent laboratories. The activity of inflammatory diseases of the joints is assessed by determining the level of the acute phase indicators ESR and C-re- 
active protein (CRP). The increase in the value of these parameters suggests high RA activity. It may also be present during periods of AS exacerbation [6]. Radiological studies performed in patients with RA revealed features of destruction of articular cartilage and bone in the form of erosions and periarticular osteoporosis, and, at a later stage, joint distortion and bone fusions. These changes are most often located within the small joints of the hands and wrists, especially in the early stages of the disease. Characteristic features of AS are calcifications in tissues near the spine in the form of syndesmophytes and bone fusions. These abnormalities concern the spine and sacroiliac joints. The typical radiological image is used to confirm the diagnosis of both diseases [3]. Among the described patients, radiological changes were typical for both RA and AS. According to some authors, in doubtful cases, in order to confirm the coexistence of both diseases, magnetic resonance imaging, scintigraphy and computed tomography may be useful in detecting early changes in the sacroiliac joints, not only in AS, but also in patients with RA $[9,15]$.

Treatment of inflammatory diseases of the joints should be comprehensive. In RA, synthetic disease-modifying antirheumatic drugs (DMARDs) should be applied as soon as possible, while in the axial form of AS without peripheral joint inflammation, drugs from this group do not apply [16]. In both diseases, high efficacy of biological drugs as TNF inhibitors was confirmed [3]. In the described patients, who had not responded to DMARDs sufficiently, biological treatment was administered with good effect. The first and third patient responded to treatment with anti-TNF- $\alpha$ (certolizumab pegol), and they are continuing this treatment. The second patient, after initial improvement during the administration of anti-TNF (subsequently etanercept, adalimumab, certolizumab pegol), has not reached a satisfactory response. In connection with the secondary ineffectiveness of anti-TNF, the patient was qualified for tocilizumab treatment. In most patients with RA coexisting with AS described during the last decade, biological treatment with TNF was administered [17, 18].

In 2014, Dundar et al. [19] described a case of a 63-year-old female patient diagnosed with coexisting RA and AS treated with rituximab with good effect after failure of TNF treatment. It seems reasonable to determine a group of patients with coexisting RA and AS, for which distinct therapeutic strategies should perhaps be developed. The first descriptions of the co-occurrence of RA and AS come from 1976.

Fallet et al. [20] described nine cases. According to them, the probability of the two diseases in one patient is from $1: 50000$ to $1: 200000$. The same year, Luthra et al. [21] published an article which described two more cases. In 1979, Major et al. [12] presented two patients and referred to 21 other examples.

In 1995, Toussirot et al. [4] described three patients, and after a review of the literature they analyzed $44 \mathrm{sim}$ ilar cases. According to these authors, a typical patient with coexisting RA and AS is a man who developed axial SpA at the age of 20-30, and who developed symptoms of peripheral arthritis after a few years. All 44 patients had inflammation of the sacroiliac joints and a positive RF. Syndesmophytes were present only in 29 patients, and HLA-B27 was positive in 40 patients out of 43 who had this antigen. Erosions typical for RA were observed in 38 patients, and rheumatoid nodules in 18 patients. Only 10 patients developed the symptoms of RA at the beginning. The probability of developing both diseases was estimated at $1: 100000$. The authors of this publication believe that accidentally detected positive HLA-B27 in a patient with RA does not influence the underlying disease and does not increase the incidence of, inter alia, inflammation of the sacroiliac joints. Similarly, a positive RF in a patient with AS does not increase the risk of erosive form of peripheral arthritis [4].

In 2011, Guo et al. [22] described a 30-year-old female patient diagnosed with concurrent RA and AS and referred to 20 other such patients described in China. The authors assume that pregnancy might be one of the environmental factors affecting the disclosure of both diseases in individuals with a positive HLA-B27 and HLADR4. They also state that until 1998, a total of 60 cases with coexistence of RA and AS had been described and another were reported between 2011 and 2014 [17-19].

In 2013, Can et al. [9] determined the incidence of IBP and other symptoms characteristic of SpA in a group of 167 patients diagnosed with RA. The criteria for IBP by Calin were met in $16.8 \%$ of patients, and enthesitis was reported in $41.9 \%$ of patients. X-ray showed features of bilateral sacroiliitis grade 3 in 4 patients (2.4\%). From among the remaining persons, 22 patients were qualified for MRI, which revealed sacroiliitis in 5 patients. In the group of 167 patients surveyed, 1.8\% met the modified New York criteria for AS diagnosis, 18.6\% met the criteria of the European Spondyloarthropathy Study Group, $15.6 \%$ met the Amor criteria and 5.3\% met the criteria of axial spondyloarthropathies according to the ASAS (Assessment of SpondyloArthritis International Society). All patients with coexistence of RA and AS had positive RF and anti-CCP [9].

\section{Summary}

Arthritis can be a symptom of many types of diseases, but thorough differential diagnostics allows for an unambiguous diagnosis in most cases. However, it should be kept in mind that one diagnosis does not 
necessarily exclude another. As shown in the cases described, coexistence of two or even more inflammatory joint diseases in the same patient can result in modification of the clinical image and an inadequate response to the treatment. Particular attention should be paid to RA patients with symptoms of typical axial SpA, and with symptoms of AS with peripheral joint involvement. Sometimes, after many years, faced with the need to verify a previous diagnosis. In a genetically predisposed patient, usually under the influence of environmental factors, which could not be precisely pinpointed, certain conditions may appear as a single episode or in an unpredictable order. In addition, the administered therapy can mask the symptoms of one of the diseases, which are then subclinical. There is also the question of whether the two diseases develop in the same patient coincidentally or some individuals are predisposed to such coexistence of the diseases. It is possible that the rarely described phenomenon of RA and AS coexistence may be more widespread than previously thought.

The authors declare no conflict of interest.

\section{References}

1. Maksymowych WP, Brown MA. Genetics of ankylosing spondylitis and rheumatoid arthritis: where are we at currently, and how do they compare? Clin Exp Rheumatol 2009; 27 (4 Suppl 55): S20-S25.

2. Kahn MF. The history of rheumatoid factor. Rev Rhum Engl Ed 1995; 62: 513-517.

3. Zimmermann-Górska I (ed.). Choroby reumatyczne. In: Interna Szczeklika. Podręcznik chorób wewnętrznych. Medycyna Praktyczna, Kraków 2014; 1791-1982.

4. Toussirot E, Acquaviva PC. Coexisting rheumatoid arthritis and ankylosing spondylitis discussion of 3 cases with review of the literature. Clin Rheumatol 1995; 14: 554-560.

5. Reumatologia kliniczna. Zimmermann-Górska I (red). T. 2. Wydanie I. Wydawnictwo Lekarskie PZWL, Warszawa 2008.

6. van der Horst-Bruinsma IE, Lems WF, Dijkmans BA. A systematic comparison of rheumatoid arthritis and ankylosing spondylitis. Clin Exp Rheumatol 2009; 27 (4 Suppl 55): S43-S49.

7. Brewerton DA, Hart FD, Nicholls A, et al. Ankylosing spondylitis and HL-A 27. Lancet 1973; 1(7809): 904-907.

8. Mera-Varela A, Ferreiro-Iglesias A, Perez-Pampin E, et al. Ultrasonographic assessment of enthesitis in HLA-B27 positive patients with rheumatoid arthritis, a matched case-only study. PLoS One 2013; 8: e58616.

9. Can G, Solmaz D, Binicier O, et al. High frequency of inflammatory back pain and other features of spondyloarthritis in patients with rheumatoid arthritis. Rheumatol Int 2013; 33: 1289-1293.

10. Appel H, Loddenkemper C, Miossec P. Rheumatoid arthritis and ankylosing spondylitis - pathology of acute inflammation. Clin Exp Rheumatol 2009; 27 (4 Suppl 55): 15-19.

11. Landewe RB, Goei Thè HS. Ankylosing spondylitis and peripheral joint disease. Clin Rheumatol 1989; 8: 87-90.
12. Major P, Resnick D, Dalinka M, et al. Coexisting rheumatoid arthritis and ankylosing spondylitis. AJR Am J Roentgenol 1980; 134: 1076-1079.

13. Raczkiewicz-Papierska A, Bachta A, Nagadowska M, et al. Czynniki predysponujące do wystąpienia zmian zapalnych i rozwoju niestabilności kręgosłupa szyjnego $u$ chorych na reumatoidalne zapalenie stawów. Reumatologia 2006; 44 : 34-40.

14. Wilson D. Rheumatoid factors in patients with rheumatoid arthritis. Can Fam Physician 2006; 52: 180-181.

15. Martínez-Cordero E, López-Zepeda J, Fonseca MC. Rheumatoid arthritis associated with ankylosing spondylitis defined by scintigraphic and CT abnormalities. Clin Rheumatol 1992; 11: 574-577.

16. Chen J, Veras MM, Liu C, et al. Methotrexate for ankylosing spondylitis. Cochrane Database Syst Rev 2013; 2: CD004524.

17. Baksay B, Dér A, Szekanecz Z, et al. Coexistence of ankylosing spondylitis and rheumatoid arthritis in a female patient. Clin Rheumatol 2011; 30: 1119-1122.

18. Azevedo VF, Buiar PG. Concurrent rheumatoid arthritis and ankylosing spondylitis in one patient: the importance of new classification criteria. Rev Bras Reumatol 2013; 53: 111-119.

19. Dundar U, Cevik H, Demirdal US, et al. Use of rituximab to treat a patient with coexistence of rheumatoid arthritis and ankylosing spondylitis: 18 months follow-up. Int J Rheum Dis 2014; doi: 10.1111/1756-185X.12303.

20. Fallet GH, Mason M, Berry $H$, et al. Rheumatoid arthritis and ankylosing spondylitis occurring together. Br Med J 1976; 1: 804-807.

21. Luthra HS, Ferguson RH, Conn DL. Coexistence of ankylosing spondylitis and rheumatoid arthritis. Arthritis Rheum 1976; 19: 111-114.

22. Guo YY, Yang LL, Cui HD, et al. Coexisting ankylosing spondylitis and rheumatoid arthritis: a case report with literature review. Chin Med J (Engl) 2011; 124: 3430-3432. 